\title{
EVALUATION OF IMPACT OF PHARMACEUTICAL CARE ON IMPROVING KNOWLEDGE AND MEDICATION ADHERENCE IN CKD PATIENTS
}

\author{
BEBIT BABY*1, CHIPPY LEE ANTONY ${ }^{\text {, SHIVIL WILSON }}{ }^{1}$, THEERTHA XAVIER ${ }^{1}$, T. TAMILSELVAN ${ }^{2}$ \\ 1PSG College of Pharmacy, Peelamedu, Coimbatore, ${ }^{2}$ Swamy Vivekanandha College of Pharmacy, Tiruchengode \\ Email: bebitbaby@gmail.com
}

Received: 05 Sep 2016 Revised and Accepted: 23 Nov 2016

\begin{abstract}
Objectives: Evaluation of the impact of pharmaceutical care on improving knowledge and medication adherence in Chronic Kidney Disease (CKD) patients.

Methods: Patient data were recorded on a data collection form after informed consent. Their knowledge and medication adherence were evaluated by questionnaire and it was quantified. Patients were counselled using patient information leaflets. Re-assessment was made during follow-up.

Results: Medication adherence among patients was classified as low, medium and high adherence. Knowledge was classified under three categories excellent, average and poor. There was a considerable improvement in knowledge and medication adherence irrespective of age and gender. The
\end{abstract} study was statistically significant with $\mathrm{P}<0.05$.

Conclusion: The efforts to increase awareness on CKD patients such as providing patient counselling and continuous education could enhance adherence to therapies and thus could improve clinical outcomes and quality of life.

Keywords: Knowledge, Medication Adherence, Chronic Kidney Disease (CKD)

(C) 2017 The Authors. Published by Innovare Academic Sciences Pvt Ltd. This is an open access article under the CC BY license (http://creativecommons.org/licenses/by/4. 0/) DOI: http://dx.doi.org/10.22159/ijpps.2017v9i1.15053

\section{INTRODUCTION}

Chronic Kidney Disease (CKD) is among the leading causes of mortality and morbidity in developing countries like India [1]. The burden of chronic disease on health care services worldwide is growing, and increased development of educational interventions which help patients to manage better their conditions are evident internationally. It has been observed that poor adherence can be a serious risk to health $[2,9]$.

Chronic illness like CKD requires multiple management strategies involving special renal dietary recommendations, fluid restrictions and complex medication regimen with more than five medications. Adequate control of blood pressure and blood sugar levels is recommended in CKD patients. In patients with ESRD adherence to dialysis schedule is essential to prevent the complications [7].

For these reasons in developed countries such as U. S. A, U. K, Australia and other European countries included a clinical pharmacist to recommend and monitor dosing, medication adherence and diet and fluid restrictions. Pharmacists are also engaged in simplifying medication regimens, proper scheduling for the administration of medicines, patient counselling, follow-up of dialysis schedule, monitoring of adverse drug reactions and drug interactions in patients with kidney disease. Pharmacist's activities showed a positive impact on patient outcomes $[8,10,11]$.

The large subcontinents such as India with a population of 1.25 crores, where regional ethnic, genetic, environmental, dietary, socio-cultural variations exist. The incidence of non-compliance is high, and it can be attributed to multiple factors such as chronic illness, forgetfulness, more number of medications, different administration techniques, dosing schedules, lack of patient-oriented counselling and education and cost of the therapy. These facts reflect the need for more clinical pharmacy services to give attention.

The present work focuses on the role of the clinical pharmacist in improving patient adherence, knowledge and outcomes and emphasises the need for clinical pharmacy services in CKD management $[3,6]$.

\section{MATERIALS AND METHODS}

Ethical approval from the Institutional Human Ethical Committee (approval number 15/024) and patient informed consent was obtained. Our interventional study aimed evaluation of the impact of pharmaceutical care on improving knowledge and medication adherence in CKD patients was performed in the Department of Nephrology for a period of six months. CKD patients who visited the Nephrology OP department and also those who were admitted to the ward, male and female patients with age more than $25 \mathrm{y}$, patients willing to give informed consent, were included in the study.

Pregnant and lactating women, psychiatric patients, patients with Acute Kidney disease were excluded. A total of 105 patients were examined. Informed consent and baseline characteristics were obtained from these patients. Out of this 92 patients were selected on the basis of inclusion and exclusion criteria.

Knowledge of patients was assessed by using patient knowledge assessment questionnaire in CKD [5]. Medication adherence of CKD patients was evaluated by Morisky 8 item questionnaire. Patients were educated and counselled by utilising Patient Information Leaflet. Follow-up of patients was done once in two months for six months. During first review 13 patients were missing. Remaining 79 were provided with education. Out of 79 patients, 69 patients were obtained for second review and 10 patients were not interested in obtaining further education. Collected data were analysed by using SPSS 19.0 Version. Numeric variables were compared by student t-test. The results were expressed in percentage and mean \pm SD. The statistical significance was set at $95 \%$ confidence interval $(p<0.05)$.

\section{RESULTS}

A total of 69 subjects were listed in this study. Subjects were classified into 3 age groups of less than $40 \mathrm{y}, 40-60 \mathrm{y}$ and greater than $60 \mathrm{y}$. Maximum subjects were found in the age group of 40-60 $\mathrm{y}$, followed by greater than $60 \mathrm{y}$ as given in table 1 . Among 69 patients, 41 were males, and 28 were females as given in table 2 . 
Table 1: Frequency distribution of age

\begin{tabular}{lll}
\hline Age group & No. of subjects & Percentage (\%) \\
\hline$<40 \mathrm{y}$ & 11 & 15.9 \\
$40-60 \mathrm{y}$ & 40 & 58.0 \\
$>60 \mathrm{y}$ & 18 & 26.1 \\
Total & 69 & 100.0 \\
\hline
\end{tabular}

$\mathrm{n}=69$

Table 2: Gender distribution in CKD patients

\begin{tabular}{lll}
\hline Gender & No. of subjects & Percentage (\%) \\
\hline Male & 41 & 59.4 \\
Female & 28 & 40.6 \\
Total & 69 & 100.0 \\
\hline
\end{tabular}

$\mathrm{n}=69$

Medication adherence among patients was classified as low adherence, medium adherence and high adherence based on Morisky 8 item questionnaire. In baseline review 49 had shown low adherence, 19 shown medium adherences and 1 were highly adhered.
In the final review, there were no subjects with low adherence and 62 subjects were found to have high adherence as given in table 3 . Mean medication adherence was compared between age groups and gender. In final review irrespective of age and gender medication adherence of all subjects improved.

Table 3: Comparison of medication adherence

\begin{tabular}{|c|c|c|c|c|c|c|c|c|}
\hline \multirow{2}{*}{$\begin{array}{l}\text { Medication } \\
\text { Adherence }\end{array}$} & \multicolumn{2}{|l|}{ Baseline } & \multicolumn{2}{|l|}{$1^{\text {st }}$ review } & \multicolumn{2}{|l|}{$2^{\text {nd }}$ review } & \multicolumn{2}{|c|}{ Final review } \\
\hline & $\begin{array}{l}\text { No of } \\
\text { patients }\end{array}$ & percentage & $\begin{array}{l}\text { No of } \\
\text { patients }\end{array}$ & percentage & $\begin{array}{l}\text { No of } \\
\text { patients }\end{array}$ & percentage & $\begin{array}{l}\text { No of } \\
\text { patients }\end{array}$ & percentage \\
\hline Low adherence $(>2)$ & 49 & 71.0 & 30 & 43.5 & 6 & 8.7 & 0 & 0 \\
\hline $\begin{array}{l}\text { Medium adherence } \\
(1-2)\end{array}$ & 19 & 27.5 & 38 & 55.1 & 52 & 75.4 & 7 & 10.1 \\
\hline High adherence $(0)$ & 1 & 1.4 & 1 & 1.4 & 11 & 15.9 & 62 & 89.9 \\
\hline Total & 69 & 100.0 & 69 & 100.0 & 69 & 100.0 & 69 & 100.0 \\
\hline
\end{tabular}

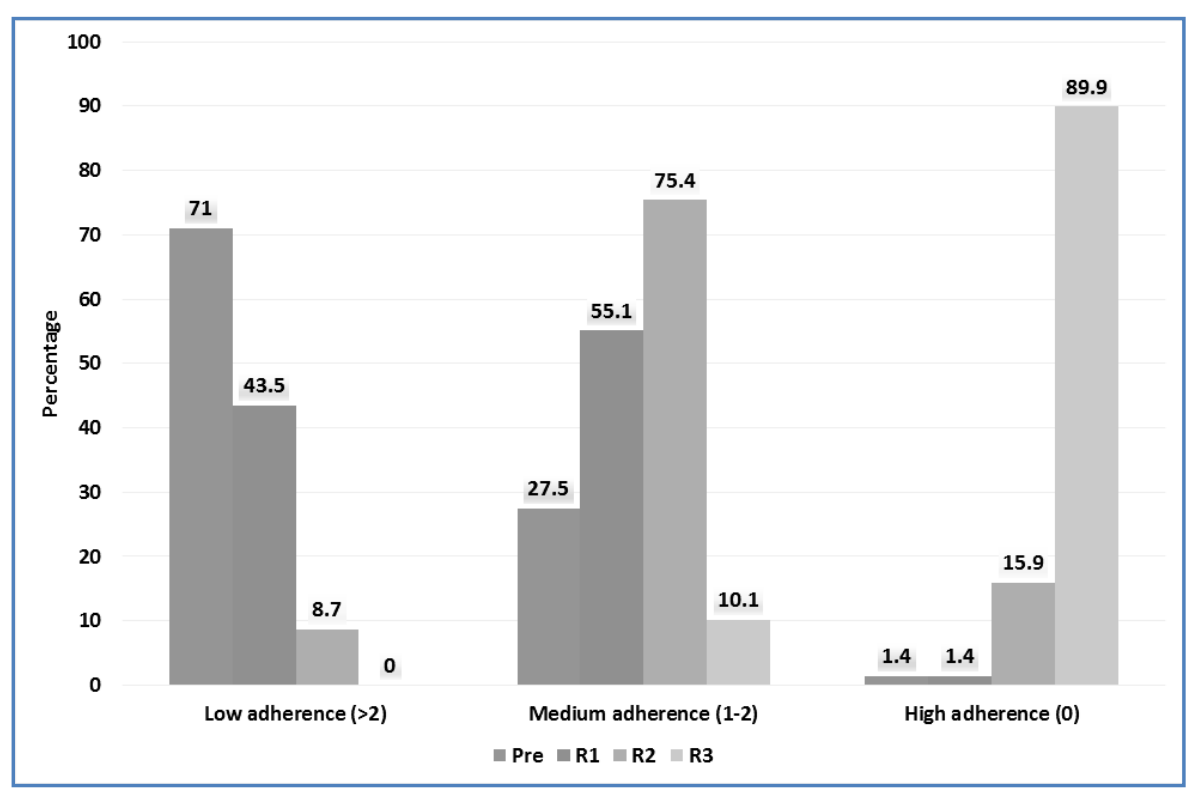

Fig. 1: Comparison of medication adherence

Note: Pre-Baseline review, R1-First review, R2-Second review, R3-Final review

Knowledge among the patients was classified under three categories excellent, average, and poor. In baseline review and first review all subjects were grouped in average and poor knowledge groups and there were no patients with excellent knowledge. In the final review, there were no patients with poor knowledge. $76.8 \%$ patients were found to have excellent knowledge in final review followed by $23.2 \%$ subjects with average knowledge as given in table 4. Mean knowledge of subjects was assessed, irrespective of age and gender knowledge of all subjects improved in the final review. 
Table 4: Percentage distribution of knowledge

\begin{tabular}{|c|c|c|c|c|c|c|c|c|}
\hline \multirow{2}{*}{$\begin{array}{l}\text { Level of } \\
\text { Knowledge }\end{array}$} & \multicolumn{2}{|c|}{ Baseline review } & \multicolumn{2}{|l|}{ Ist review } & \multicolumn{2}{|l|}{$2^{\text {nd }}$ review } & \multicolumn{2}{|c|}{ Final review } \\
\hline & $\begin{array}{l}\text { No of } \\
\text { patients }\end{array}$ & percentage & $\begin{array}{l}\text { No of } \\
\text { patients }\end{array}$ & percentage & $\begin{array}{l}\text { No of } \\
\text { patients }\end{array}$ & percentage & $\begin{array}{l}\text { No of } \\
\text { patients }\end{array}$ & percentage \\
\hline $\begin{array}{l}\text { Excellent } \\
\text { (7 points) }\end{array}$ & 0 & 0 & 0 & 0 & 1 & 1.4 & 53 & 76.8 \\
\hline $\begin{array}{l}\text { Average } \\
(\geq 4 \text { points })\end{array}$ & 9 & 13.0 & 37 & 53.6 & 67 & 97.1 & 16 & 23.2 \\
\hline $\begin{array}{l}\text { Poor } \\
\text { (<4 points) }\end{array}$ & 60 & 87.0 & 32 & 46.4 & 1 & 1.4 & 0 & 0 \\
\hline Total & 69 & 100.0 & 69 & 100.0 & 69 & 100.0 & 69 & 100.0 \\
\hline
\end{tabular}

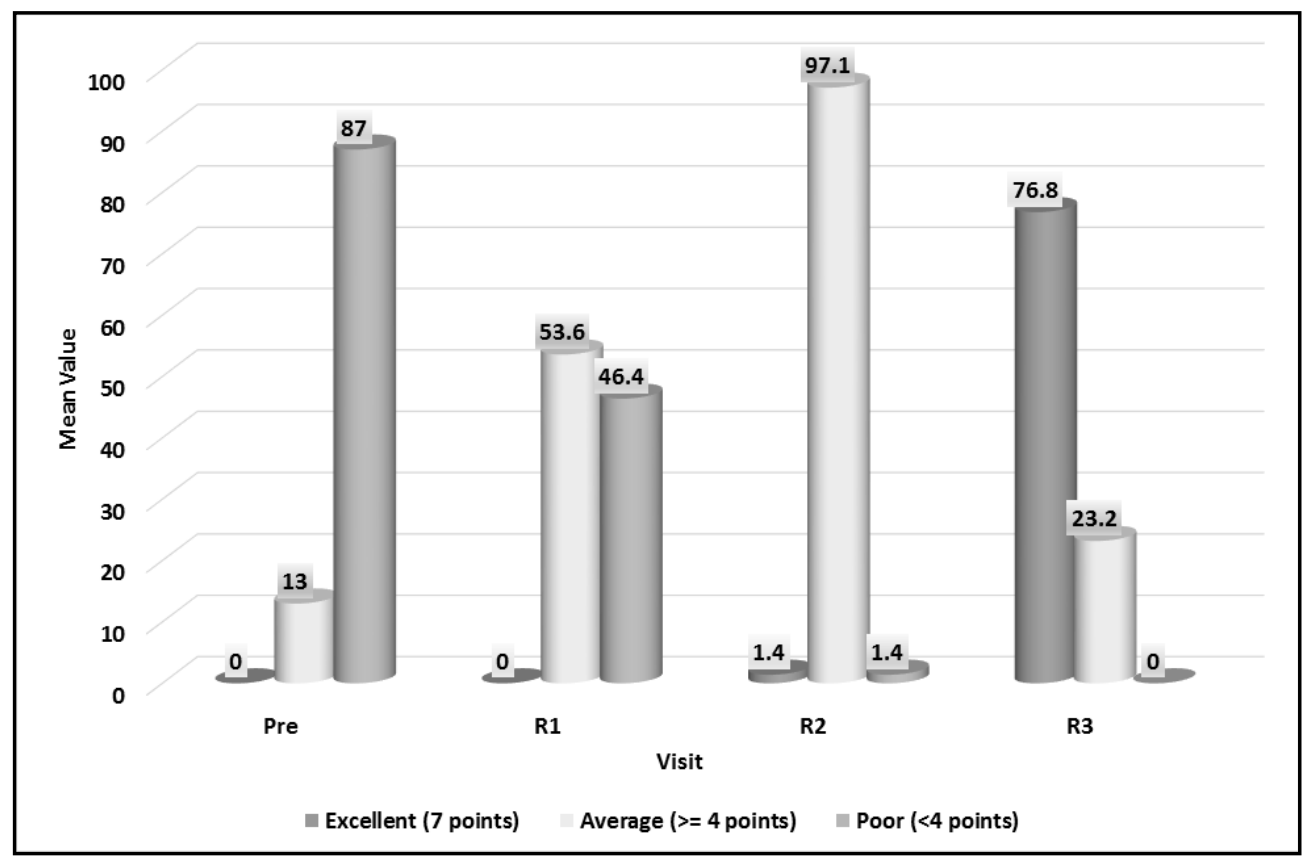

Fig. 2: Percentage distribution of knowledge

Note: Pre-Baseline review, R1-First review, R2-Second review, R3-Final review

\section{DISCUSSION}

The majority of the patient population was under the age group of 40-60 y. The mean age of male and female groups was 55.93years and 48.18 y respectively. About $59.4 \%$ of patients were male and remaining $(40.6 \%)$ being females.

Medication adherence was classified as low, medium and high adherence. Medication adherence was low during the baseline visit which was improved to high adherence through continuous education by using patient information leaflets. A patient with low adherence during the first visit was $71 \%$ which were gradually reduced, and patients with high adherence during the baseline visit were $1.4 \%$ which later improved to $89.9 \%$ in the final review. The mean value of medication adherence was $4.12 \pm 1.92$ (low adherence) during baseline visit which later decreases to $0.14 \pm 0.463$ (high adherence). Thus there is a significant ( $p>0.05)$ improvement in medication adherence at the end of the study. In a study E. J. C. Magacho, et al. [4] compared baseline adherence with final review among the dialysis patients and concluded that non-adherence to medication was identified in $17.4 \%$ of patients with kidney disease and increased during the next 12 mo of the disease course to $26.8 \%$.

In our study population, only one patient was in high adherence group with 49 patients in low adherence during the baseline visit. It dramatically changed to 62 patients in high adherence group with none in the low adherence group during the final visit. Upon correlating age group with medication adherence in the final visit, there was no correlation which shows that after giving the patient counselling irrespective of age group adherence had improved. Thus our study shows that medication adherence is not correlated with age ( $\mathrm{p}>0.05)$. A study Dena E. Rifkin, et al. [5] shows that there is no significant difference in adherence among different age groups.

Knowledge assessment was categorised into three group's excellent, average and poor group. During baseline review knowledge assessment value was 1.75 (poor knowledge) and which was improved to 6.65 after continuous education. During the baseline review patient with excellent knowledge was $0 \%$ which later improved to $76.8 \%$ in the final visit. The mean knowledge score during baseline visit was $1.75 \pm 1.52$ which improved to $6.65 \pm 0.68$ during the final visit. In our study, there is a significant $(p>0.05)$ improvement in patient knowledge after providing patient education through patient information leaflets. A cross-sectional study Moreira L, et al. [6] concluded that medication non-compliance prevalence was high among the CKD patients. The non-compliance associated factors identified in CKD were the patient's poor knowledge regarding therapy and dissatisfaction with health care service provided.

In the study population, 11 subjects were found in the age group less than 40, 40 subjects were in the age group 40-60 y and 18 subjects were aged more than $60 \mathrm{y}$. Patients with age group less than 40 had more baseline knowledge compared to other groups. After continuous education, knowledge of 3 age groups improved.

\section{CONCLUSION}

In the present study, the impact of structured education showed significant improvement on knowledge about disease and 
medication adherence in CKD patients. This will enhance the awareness of patients on chronic kidney disease. As per the study results medication non-compliance prevalence was high among the patients studied. Lack of access to medicines remains an important health care problem. The non-compliance associated factors identified in CKD were the patient's poor knowledge regarding disease condition and therapy. Medication education provided by clinical pharmacists resulted in a considerable increase in medication adherence and knowledge at the end of the study. Thus our study concludes that efforts to improve awareness on CKD patients such as providing patient counselling and continuous education could enhance adherence to therapies and thus could improve clinical outcomes and quality of life.

\section{CONFLICT OF INTERESTS}

Declared none

\section{REFERENCES}

1. Agarwal SK, Srivastava RK. Chronic kidney disease in India: challenges and solutions. Karger Nephron Clin Practice 2009;3:111-97.

2. Hala I, Abo Deif, Mohga Selim. Effect of an educational programme on adherence to therapeutic regimen among CKD stages five patients under maintenance hemodialysis. J Education Practice 2015;6:21-33.

3. Stephanie Belaiche, Thierry Romanet, Robert Bell, Jean Calop, Benoit Allenet, Philippe Zaoui. Pharmaceutical care in chronic kidney disease: experience at Grenoble University Hospital from 2006 to 2010. J Nephrol 2012;25:558-65.

4. EJC Magacho, LC Ribeiro, A Chaoubah, MG Bastos. Adherence to drug therapy in kidney disease. Brazilian J Med Biol Res 2011;44:258-62.
5. Dena E Rifkin, M Barton Laws, Madhurmathi Rao, VS Balakrishnan, Mark J Sarnak, Ira B Wilson. Medication adherence behaviour and priorities among older adults with CKD: A semi-structured interview study. Am J Kidney Dis 2010;56:439-46.

6. Moreira LB, Fernandes PF, Mota RS, Monte FS, Galvao RI, Sousa $\mathrm{DF}$, et al. Medication noncompliance in chronic kidney disease. Jnephrol 2008;21:34-62.

7. Wei Leng Chow, Veena D Joshi, Aung Soe Tin, Saskia Van der Erf. Limited knowledge of chronic kidney disease primary care patients a cross-sectional survey. BMC Nephrol 2012;13:471-99.

8. Gunar Stemer, Rosa Lemmens-Gruber. Clinical pharmacy activities in chronic kidney disease and end-stage renal disease patients: a systematic literature review. BMC Nephrol 2011;12:35-42.

9. Vanitha Rani. The impact of continuous patient counselling on knowledge, attitude, and practices and medication adherence of diabetic patients attending outpatient pharmacy services. Asian J Pharm Clin Res 2016;9:364-9.

10. Vanitha Rani. The impact of clinical pharmacist provided education on medication knowledge and adherence of hemodialysis patients in a south Indian university hospital. Asian J Pharm Clin Res 2013;6:24-7.

11. Rouzaud-Laborde Charlotte, Damery Lea1. Aspirin, patient knowledge and pharmaceutical information after a stroke. Int J Curr Pharm Clin Res 2015;5:119-23.

\section{How to cite this article}

- $\quad$ Bebit Baby, Chippy Lee Antony, Shivil Wilson, Theertha Xavier, $\mathrm{T}$ Tamilselvan. Evaluation of the impact of pharmaceutical care on improving knowledge and medication adherence in CKD patients. Int J Pharm Pharm Sci 2017;9(1):63-66. 